\title{
OBITUARIES
}

\section{Sir Leonard Bairstow, C.B.E., F.R.S.}

THE death of Sir Leonard Bairstow on September 8 deprives us of one of the few remaining pioneers of aviation: a man whose meticulous analytical and experimental study of aerodynamics helped to secure the foundations of that subject at a time when the theory of flight was barely more than an expression of the physical courage of those who practised it.

Sir Leonard was born in Halifax, Yorkshire, on June 25,1880 , and, after obtaining a diploma in mechanics at the Royal College of Science, London, he joined the staff of the National Physical Laboratory. His work there encompassed most of the then current problems of aerodynamics: bolloons, airships, seaplanes, propellers, the design of wing sections, wind tunnels, and aeroplane performance as well as its structure. Among his collaborators were such men as Arthur Fage, Sir Melvill Jones and Ernest Relf, who themselves were later to become, and still remain, outstanding figures in the field of aviation. His scientific papers written during that period, many of them published before the First World War, and describing experiments made in wind tunnels, could well serve as models of thoroughness and clarity to the modern student of aerodynamies; the assumptions-and there were necessarily many of them at that time--were boldly displayed and the purely experimental details described so carefully, yet with astonishing succinctness, that one could reproduce without difficulty his apparatus and techniques to-day. But perhaps his most important contribution was made on the mathematical side and concerned the analysis of the stability of aeroplanes. By 1913 he had helped to consolidate the theory of stability and, continuing the work of Bryan, to cast it broadly into the form in which it now exists: a subject which continued to preoccupy him for many years.

Elected to a fellowship of the Royal Society in 1917, Bairstow was awarded the C.B.E. in the same year.

He left the National Physical Laboratory in 1919 to become professor of aerodynamics in the newly formed Department of Aeronauties at the Imperial College of Science and Technology, London, but not before he had played a major part in detaching the Aerodynamics Division from the Engineering Division and giving it a separate identity. In fact, he is regarded as the first superintendent of the Aerodynamics Division as we know it to-day. In 1923, succeeding Sir Richard Glazebrook, he became Zaharoff professor of aviation and head of the Aeronautics Department, a chair which he occupied until his retirement in 1945. Once again Sir Leonard was to take an important part in guiding the destiny of aeronautics in Great Britain, for during his tenure of the chair the study of aerodynamics evolved from a largely empirical assembly of facts- "the subject of aerodynamics is almost wholly based on experiment" Sir Leonard said in 1919-to an orderly and self-consistent science in its own right, and attracted students in increasing numbers. Many of the present-day authorities on aeronautical matters in industry, in Government service and in universities had at one time studied under him.

While Zaharoff professor at Imperial College, he was doeply involved in the work of the Aeronautical Research Council, of which he was a member, with a few short interruptions, for some thirty-five years. He was vicechairman of the Council during 1940-45 and its chairman during 1949-52. He was also vice-president of the Royal Aeronautical Society from 1930 until 1934. He received a knighthood in 1952 .

Many of Sir Leonard's achievements are so firmly embedded in the foundations of aeronautical develop- ment as to be easily taken for granted or even overlooked by future generations of workers in the subject; more durable evidence of his distinction is provided by his book, Applied Aerodynamics. Published in 1919, it was the first comprehensive text-book on the subject and remained so for many years. Indeed, the second edition was reprinted as late as 1944 , a remarkable tribute to a work that was fashioned while the subject was still in its infancy. In the preface to the first edition, Bairstow wrote: "The main outlines of the theory of flight are simple, but the stage of application now reached necessitates careful examination of secondary features". Since these words first appeared, their truth may for a time have been in doubt when the outlines of the theory became blurred by the complex interaction between the motion of a high-speed aeroplane and the forces exerted on it by the compressible medium through which it travelled. But now, when flight is taken to include the penetration of outer space by means of rockets, Bairstow's view of the problem regains its force and takes on the quality of prophecy, for so simple are the outlines of the theory of rocket flight that they are accessible to every schoolboy; it is the 'secondary features' that occupy the minds of aerodynamicists and account for a solid proportion of their present researches.

Sir Leonard married in 1907 Eleanor Mary Hamer, who died in 1926, and by whom he had a son and a daughter. In 1930 he married Florence Katharine, elder daughter of D. J. Stephens, of Llandaff.

P. R. OWEN

\section{Prof. Hans Kopfermann}

Hans Kopfermann, who died on January 26, will be missed by many friends and colleagues throughout the world-wide scientific community. His tall boyish figure belied his age: he would have been sixty-eight in April and was to retire this summer from the post of director of the First Physical Institute of the University of Heidelberg.

Among the present generation of physicists he is best known for his spectroscopic researches on isotope shift and nuclear hyperfine structure and as the author of a comprehensive monograph on nuclear moments. This represents but one facet of a full life's work which for nearly four decades has moved remarkably close to the crest of the advancing wave of physics.

Born in 1895 in Breckenheim near Wiesbaden, he went to the University of Göttingen in the early 'twenties, the golden years of intense experimental and theoretical activity marking the final phase of the largely heuristic quantum theory of classical particles. He worked for his doctorate under the creative guidance of James Franck. His thesis on sensitized fluorescence of lead and bismuth vapour was published in 1924, a year before Heisenberg, as a very young Privatdozent in Göttingen, burst into physics with his new ideas of a quantum mochanies, in which the Kramers dispersion theory played such a decisive part.

Thus it was Kopfermann's good fortune-or Frank's wise direction - that his first post-doctoral appointment led him to the Kaiser Wilhelm Institut in Berlin-Dahlem to contribute as assistant of Ladenburg to a long series of investigations on the anomalous dispersion of excited atoms which provided many experimental tests of the predictions of quantum mechanies and culminated in 1928 in the first experimental evidence for negative dispersion. In careful experiments on the dispersion around several neon lines for varying conditions of electric excitation of the gas discharge he established the existence of the effect of stimulated emission corresponding to 
transitions from higher to lowor atomic energy levels induced by the incident light. This represents negative dispersion since it opposes the effect of absorptive transitions from lower to higher levels. In retrospect this work appears as an important landmark on the long road from Einstein's conception of the ides of stimulatod omission in 1919 through the various radio froquency and micro. wave magnetic resonances which are dominated by the competition between stimulated emission and absorption, to crystal masers and finally, ending not far from the starting point, to tho helium-sensitized neon gas laser with its immonse possibilities for research and technologies.

Kopfermann's first work on nuclear hyperfine structure and isotope shift overlapped the final phases of his work on negative dispersion which involvod high-resolution tochniques. Working under the same roof with Hahn and Lise Meitner, and not far from the Einsteinturm in Potsdam whore Schüler had pioneered the hollow cathode cooled light source, he was naturally attracted to this very fruitful fiold of application of spectroscopy which in one form or another was to be his main intereat for the rest of his life.

A period in Bohr's Institute in Copenhagen, whore he collaborated with Rasmussen on a numbor of problems of hyperfine structure, had a profound infuence on him. $\mathrm{He}$ shared with Bohr an essential humility, epitomizod by the Nur um zu lernen (only in order to loarn), one of the many Bohrisms which Kopformann used to quote and to live by. Indeed, those fortunate to have worked with or under him will remember him, above all, as the true mentor and friend who guided them through their difficulties and whose deep insight into the essential physics beyond the immediate experimental problems inspired them to do their best creativo work.

On return to Berlin he became Privatdozent at the Univorsity, still continuing his work on nuoloar hyperfine structure and isotope shift in the Kaiser Wilhelm Institute, but later moved to Gustav Hertz's Institute at the Tochnischo Hochschule, Berlin. It was hero that he initiated projects on the separation of isotopes for nuclear spectroscopy which fitted in with Hertz's interests at the timo, and were carried out by Walcher and Paul, his faithful collaborators for the next ten years.

In 1937 he took up his first chair in the University of Kiel. In the difficult pre-war period and under the restricted conditions of a small University, the pace of experimental work had to slow down. Kopfermann utilizod this interval for writing his book on nuclear moments in which he showed a romarkable grasp of a subject which was then in its beginning, and a clear vision of its significance for the understanding of nuclear structure. So much so, that the Kernmomente of 1956-or its English version of 1958-was truly a second edition, unchanged in plan and conception but expandod to almost twice the size of the original book by the lucid and original presentation of all the new developments of the post-war era, such as nuclear resonance techniques.

The call to Göttingen which Kopfermann followed in 1942, to occupy the chair at the Second Physical Institute from which his great teacher, James Franck, had felt compelled to resign in 1933, must have filled Kopfermann with pride and sadness, for his attitude vis-dे-vis the Nazi régime was uncompromising and without reproach. His loyalty was to his frionds and to science, and there are many who will remember Kopfermann's active help with gratitude.

Göttingen, which had escaped serious destruction, became in the immediate post-war years a haven whore the elite of German science, v. Laue, Heisenberg, Weizsäcker, etc., congregated. It was during this period that, apart from notable work with Paul on the Lamb shift in helium, Kopfermenn made his most outstanding contribution to the study of nuclear structure. In collaboration with Brix, he discovered jumps in the relative isotope shift of heavy elements which ho related to the quadruple momont and deformation of the nuclei, ideas which led Aage Bohr and Mottelson to the dynamical modol of the nucleus. In the same period, Dehmelt and Krüger in auguratod under his inspiration the method of nuclear electric quadruple resonance which now, liko nuclear magnetic resonance, occupies an important place in the study of the oloctronic structure of molecules.

It may be less well known that Kopfermann initiated and supported research in puro nuclear physics, particularly nucloar photo effects. This goes back to the war-time, when very soon after Kerst's first publications he persuaded Paul to develop a betatron. The first machine was completed about the end of the War. Undaunted by the strict regulations of the military government which forbade its use for nuclear studios, Kopfermann collaborated with his medical colleagues on methods of diroct electron therapy which appeared very promising at the time. His fine article in the Ergebnisse der Exakten Naturwissenschaften on the "Elektronenschleuder" ("electron sling' for betatron, a valiant, but alas unsuccessful, atternpt to stem the flood of pseudo-Greek atrocities) reflects the enjoyment and active interest which Kopfermann took in these more technical developments.

Kopfermann's move to his last station marked the beginning of a more prosperous era so far as material support for scientific research in Germany was conoerned. Under his direction the Physical Institute at Heidelberg has developed into one of the best-equipped and mostproductive laboratories for the study of the nuelous by atomic spectroscopy, atomic beam methods, various typers of optical double resonance, by accelerators and other techniques of more strictly nuclear physios. Up to the last he took a very active part in the rosearches, inspiring and encouraging his devoted students and collaborators. To see so many of them in leading positions in univorsities and industry, eight in important chairs in Germany, two in chairs in tho United States, must have given him deep satisfaction. Although he shied away from official positions, his views commanded great respect, and in the background ho oxercised a beneficial influence on the higher direction of science and physios in Germany.

Kopfermann had many interests outside physics. To join in chambor music on his viola in a small circle of his colleagues and friends was his great joy and happinoss. The warm glow and youthful freshness of his personality endoarod him to all who met him. E. E. SCHNEIDER

\section{Prof. E. B. Moullin}

The death of Prof. Fric Balliol Moullin on September 18 at the age of seventy will have saddened many members of the electrical engineering profossion, and particularly those who were privileged to be old students of his at Cambridge or. Oxford.

$\mathrm{H}_{e}$ was born on August 10, 1893, at Sandbanks, near Swanage, and his later attachment to radio frequency measurements may have been influenced by the fact that his birthplace was within a fow hundred yards of the site of the first wireless mast set up in Britain by Marconi. $\mathrm{H}_{e}$ was educated privately and learned at home the mathematics which won him a scholarship at Downing College, Cambridge. $\mathrm{H}_{\theta}$ took first-class honours and was the John Winbolt Prizeman in the Mechanical Sciences Tripos. Owing to a breakdown in health he was unfit for military service in the First World War, but taught for part of this period at the Royal Nuval Collogo, Greenwich, before returning to Cambridge in 1919 as university lecturer in engineering, and member of King's College.

At the time radio -or wireless as it was then calledwas in its infancy, and Moullin wes among the first to devise accurate means of measuring the characteristics of components, circuits and radiating systems for use at radio froquonsies. His invention in the early 1920 's of the 